\title{
FUNDAMENTOS DE LA SEMIÓTICA JURÍDICA. HACIA UNA SEMIÓTICA DEL DERECHO PENAL
}

Manuel Fernando Moya Vargas*

\begin{abstract}
Resumen: Historiográficamente, el Derecho se caracteriza por el predominio de la hermenéutica y de la dogmática. Esta condición se manifiesta en una epistemología cuyo método ha enseñoreado el aspecto técnico del saber jurídico. Consecuencia de lo cual ha sido, como sucede con la mayor parte de las ciencias sociales y humanas, la discreta importancia que han terminado otorgando a la sociedad y al ser humano, a los cuales reducen en tanto legos, a nudos e impotentes destinatarios de las instituciones jurídicas. De esta forma, el Derecho ha sido capitalizado por los técnicos, quienes se han desembarazado de "los demás", transfiriéndolos a la sociología jurídica, la cual sin embargo no ha tenido por empeño el desarrollo de la ciencia del Derecho. En contraste, la semiótica del Derecho, semiótica jurídica o semiótica de la justicia, reivindica al ser humano y a las sociedades, en tanto las restablece en su condición auténtica de comunidades de hablantes del Derecho que, a través de procesos comunicativos para los cuales usan los signos jurídicos, crean y transmiten su propio sentido de justicia.
\end{abstract}

\footnotetext{
Abogado de la Universidad Externado de Colombia, Doctor en Sociología Jurídica e Instituciones Políticas, Posdoctorante en Derecho de la Universidad de Buenos Aires. Investigador Senior ante Colciencias. Bogotá, Colombia. Correo-e: manuelfernandomoyavargas@ gmail.com. Fecha de recepción: 19 de abril de 2017. Fecha de aceptación: 15 de enero de 2018. Para citar el artículo: MANUEL Fernando Moya VARgas. "Fundamentos de la semiótica jurídica. Hacia una semiótica del Derecho penal", en Revista Derecho Penal y Criminología, Vol. 38, n. ${ }^{\circ}$ 105, julio-diciembre de 2017, Bogotá, Universidad Externado de Colombia, pp. 179-206. DOI: https://doi.org/10.18601/01210483.v38n105.08
} 
Palabas clave: Derecho, Derecho penal, Semiótica jurídica.

\title{
FUNDAMENTALS OF SEMUIOTICS OF LAW. TOWARDS A SEMIOTICS OF CRIMINAL LAW
}

\begin{abstract}
Historiographically, the right is characterized by the predominance of hermeneutics and the dogmatic. This condition manifests itself in an epistemology whose method has engulfed the technical aspect of legal knowledge. Consequence of which has been, as it is the case with most of the social and human sciences, the discreet importance granted to the society and the human being, which reduces as lay, knots and helpless recipient of legal institutions is over. In this way the law has been capitalized by technicians, who have got rid of "others", by transferring them to the legal sociology, which however has not had by commitment to the development of the science of law. In contrast, the semiotics of law, semiotic semiotics or legal justice, claims human beings and societies, insofar as it re-establishes in its authentic condition of communities of speakers of the right to, through communication processes for which used legal signs, create and transmit their own sense of Justice.
\end{abstract}

Keywords: Law, Criminal Law, Semiotics of law.

\section{INTRODUCCIÓN}

Nos hemos acostumbrado a un saber científico del Derecho cuya principal característica consiste en provenir de investigaciones epistemológica y metodológicamente dominadas por la hermenéutica y la dogmática. La sociología del Derecho, por su parte, ha sido un importante panóptico crítico favorable al desarrollo de la política judicial, de la política legislativa, de la política penal y, en fin, del control jurídico, pero no propiamente de la ciencia del Derecho.

Si tomamos como línea de base el llamado Derecho clásico ${ }^{1}$, es posible descubrir el marcado acento hermenéutico que se impuso hegemónicamente, hasta cuando los estudios sobre filosofía del Derecho empezaron a proyectarse en las realidades constitucionales de los pueblos. Momento que historiográficamente corresponde al tránsito vivido por la comunidad feudal en consideración a la Revolución Francesa.

1 Por tal entendemos el Derecho pensado esencialmente por los llamados juristas clásicos, producido aproximadamente entre el siglo II a.C. y el siglo III de C., enfocado principalmente en la generación de un Derecho universal, promovido desde el imperio romano y actualizado continuamente mediante la labor de los pretores, principalmente el peregrino, encargado de afinar el Derecho romano propiamente dicho con el Derecho extranjero de las provincias conquistadas y que resultaban afines a Roma. Iglesias R., JuAn (1993) Derecho Romano, Historia e Instituciones, Barcelona: Ariel Editorial. 
A partir de la obra de Kant, la dogmática jurídica se consolidó, cuyo empeño claramente estuvo orientado a la fundamentación sistémica integral del Derecho ${ }^{2}$, con base en el principialismo. Más adelante y poco después, Hegel, a través de los Principios de la Filosofía del Derecho, dio un remezón que contribuyó de forma definitiva a la consolidación de la dogmática ${ }^{3}$.

Tal vez convenga aclarar que esto no implicó la ruina de la hermenéutica, antes bien y en muchos casos su consolidación, pero desde entonces debió compartir con la dogmática la producción científica del saber jurídico, y muchas veces ceder a su favor.

Ahora bien, toda epistemología y todo método en que se apoya busca el sentido de los fenómenos. Su bramante ha consistido en hacerlos emerger a la conciencia, para así poder impactarlos, cuando no para comprender esa imposibilidad. Si bien tendremos ocasión de asumir en algún grado la teoría del sentido, anticipamos que tiene que ver con lo más puro de la creación humana, pues el sentido informa acerca de lo que se puede y quiere hacerse con algo. Es por ello que la epistemología jurídica y sus métodos crean conciencia acerca de lo que pueden o no ser las instituciones jurídicas.

De la historiografía jurídica surge que la hermenéutica se ha empeñado en desentrañar el sentido del Derecho a partir de sus interioridades, especialmente dentro de las instituciones jurídicas con una muy acentuada preferencia por las normas, de su sofisticación en términos de interpretación y consumación lingüística. Mientras que la dogmática se ha caracterizado por hacer un recorrido muchas veces contrario, en cuanto busca el sentido en el entorno, y por ello su obsesión con los principios constitucionales ${ }^{4}$. Por supuesto, la trampa hermenéutica que le ha sido nada fácil de fraguar, es la posibilidad siempre presente de reducir los principios a instituciones jurídicas de las cuales dé mejor cuenta la hermenéutica.

Nada de cuestionable han tenido las dos, y antes bien es mucho -casi todo, lo que en materia de ciencia jurídica les debemos.

No obstante siempre ha estado latente el peligro de precipitar el estatuto científico del Derecho en el hoyo negro dentro del cual han sucumbido todas las ciencias sociales y humanas, hasta ser tan poco sociales y menos aún humanas, como nunca antes se habían conocido.

2 Kant, Inmanuel (1995). La Metafísica de las Costumbres. Traducción de Adela Cortina, Bogotá: REI Andes Ltda.

3 Hegel, G.W. Friedrich (1999). Principios de la Filosofía del Derecho. Traductor Juan Luis Vermal, Barcelona: Edhasa.

4 La expresión entorno la empleamos aquí en la misma configuración que le otorga Luhmann la de umwelt. Luhmann, Niklas (2007). La sociedad de la sociedad, México: Herder, pp. 40-55, 737, 762-763. 
Ese hoyo negro a nuestro juicio consiste en la transubstanciación del objeto de conocimiento. Al respecto, no es demasiado difícil encontrar que del lugar asignado a la sociedad y al ser humano como objetos de conocimiento, han sido irreductiblemente desplazados por las teorías acerca de la sociedad y del ser humano, para las cuales estos cuentan cada vez menos ${ }^{5}$.

No pretenderíamos que ese desastre se deba a la hermenéutica o a la dogmática, pero sí a los usos que de ellas se han hecho respecto del Derecho. De un cierto uso de la hermenéutica las normas terminaron siendo más importantes que la solución de las divergencias que las suscitaron históricamente. De una cierta incursión dogmática en las instituciones jurídicas, la sociedad fue todavía más reducida a un nudo destinatario del Derecho, ya no tanto manifiesto en normas como en principios superiores.

Paradójicamente, muchos maestros del Derecho han advertido acerca de la distancia que existe con lo social.

Pero si hay algo de cierto en ello, no se debe a que el Derecho sea en sí mismo artificial y fallidamente ortopédico, a no ser que carezca de otra opción de escena que el teatro de sombras hermenéuticas y dogmáticas, en el cual, mediante sofisticadas logomaquias, transfirieron la sociedad al capital heurístico de la sociología jurídica, y del ser humano se desentendieron todas hasta forjar un paralelismo inquebrantable entre él y las instituciones jurídicas. Hermenéutica y dogmáticamente el conocimiento del Derecho es capital simbólico de los técnicos, inicialmente del Colegio Pontifical, luego de los juristas y finalmente de los abogados ${ }^{6}$.

Sin embargo, no hay un sin remedio, pues existe otra posibilidad. En el horizonte científico del Derecho tenemos una opción epistemológica caracterizada por encontrar el sentido del Derecho en el ser humano y en la sociedad, a los cuales reconoce como fuente de la justicia, y frente a las instituciones jurídicas el que se encarga de su individuación.

Esa opción es la semiótica del Derecho, al semiótica jurídica o, como ha sido nuestra preferencia, la semiótica de la justicia.

No podemos pretender que "la hayan inventado recientemente", más bien de lo que no dudamos es que es tan ancestral como la hermenéutica y la dogmática, pero al igual que estas en algún momento histórico, no ha sido la preferida por los científicos

5 Quizás esto explique una paradoja, ¿cómo es que muchos de los grandes humanistas, teóricos sociales, y hasta guías espirituales, nada les incomode tanto como otro ser humano al lado? Y terminen atentando contra su dignidad con tanta o mayor solvencia que aquellos contra los cuales se viven pronunciando.

6 Cfr. IgLesias, JuAN. 
del Derecho, lo cual puede tener explicaciones que ahora mismo no nos interesan. Lo importante es que a partir de los trabajos de Roberta Kevelson, empezaron a ser oídas con mejor disposición las nuevas composiciones científicas que puede hacerse del saber jurídico.

Pero ese eco pareciera no haber ido hasta ahora más allá de Norteamérica y algunos sectores de Europa. Mientras que Iberoamérica ha tendido cuando no a desentenderse, sí a contraer la semiótica del Derecho a un sola de sus vertientes, que es precisamente la iuris-lingüística ${ }^{7}$.

Nos hemos propuesto presentar resultados de investigación y reflexiones de base semiótica. Esto por cuanto nos interesa tanto divulgarla como que se desarrolle en un país en cuya transición puede verse significativamente redivivo en su administración de justicia, sobre la base de una nueva conciencia jurídica.

Si bien hemos sido quienes se orientan hacia el estudio del Derecho penal sobre el presupuesto semiótico, un enfoque deductivo nos sugiere dar inicio a ese proceso de desarrollo, presentando inicialmente los presupuestos esenciales sobre los cuales descansa la semiótica jurídica en general, desde luego procurando introducir en el estudio concreto de la semiótica penal.

Por último, es prudente advertir que en tanto la alternativa semiótica ofrece al Derecho un horizonte de saber muy distinto al de tradición hermenéutica y dogmática, no obstante que pueda haber convergencias tal vez sean más recurrentes las discrepancias. Por no hacer parte de la formación de tradición pandectística, su lenguaje suele ser desconocido al jurista -cuando menos al iberoamericano-, lo cual acentúa su connatural complejidad.

Hay investigaciones que pese a los esfuerzos y solidez con que se gestan y concluyen, tienen tantas posibilidades de aceptación por parte de la comunidad científica, como las tendría el intentar levantar una piedra con una pluma. Efecto que no se explica por causas vinculadas a sus fundamentos ni a sus conclusiones, sino por algo que la historia registra como la levedad espiritual en cierto tipo de ser. Esto se debe a las conciencias obcecadas, timoratas y frecuentemente vacuas, que suelen guardarse del riesgo de cambiar mediante la negación, lo cual en materia de ciencia se manifiesta por el señalamiento, más angustioso que precipitado, de investigaciones "mal hechas". Epitafio bajo el cual descansan en tumbas vacías las posibilidades de la alteridad.

Esta investigación y todas las que en materia de Derecho provienen de la semiótica, son de esas, las mismas que Nietzsche habría llamado "dionisiacas". Tenemos ra-

7 Robles Morchón, Gregorio (2009). Comunicación, Lenguaje y Derecho: algunas ideas básicas de la teoría comunicacional del Derecho. Madrid: Real Academia de Ciencias Morales y Políticas. 
zones para concluir que no es tanto que estén mal hechas, como que son profundamente distintas. Por consiguiente, no sirven para saber lo que ya se sabe, sino para todo lo contrario.

Sin embargo, anticipamos que pese a los disgustos que pueda provocar, entiende la justicia como la condición inmanente de la convivencia pacífica, y que habita en cada ser de manera semejante como la salud habita en el ser y por ello no hay que buscarlas fuera de él.

\section{ASPECTOS GENERALES DE LA SEMIÓTICA ${ }^{8}$}

Esta investigación tiene por objetivo estructurar el método de la semiótica jurídica aplicada al Derecho penal en particular, y al Derecho en general. Para ello y con un enfoque eminentemente deductivo, se han asumido los aspectos precisos de la semiótica general con su proyección sobre la semiótica jurídica específicamente.

No ha sido sencillo por razones diversas, y hemos preferido iniciar, como ha sido costumbre, por precisar el estatuto científico de la semiótica. Al respecto hallamos que las aproximaciones epistemológicas han venido enredándose en lo que creemos es una peligrosa medianía. Ese riesgo consiste en pretender estrechar la semiótica en general, al estudio de los signos.

Observación un tanto descriptiva y un tanto cuestionadora. Lo primero, porque no podemos disputar que en un momento dado de la historia, la semiótica ha sido efectivamente reducida al estudio de los signos, más precisamente de los sistemas de signos. Es preciso señalar que se trata de una vicisitud histórica que en manera alguna ha transformado la epistemología semiótica, pero no desconocemos que crea confusión. Y esa confusión, a nuestro juicio, comienza a desenredarse dejando en claro que puede haber habido epistemes semióticas cuya proyección quiera desentenderse de los procesos de comunicación y sobre todo, del sentido.

Es una reducción cuya falsación surge de la misma naturaleza del signo, que en sí compromete los procesos comunicativos y al sentido, puesto que un signo que no sirva para comunicar y que tampoco curse como precursor del sentido, es inconcebible. De hecho, no hay "signo nada más que para mí", esto es, que solo signifique algo que nadie más que el "sí mismo" pueda decodificar, pues el tipo de relación

8 También conocida como "semiótica jurídica", debemos decir que no es la nominación que más nos gusta, pues tenemos razones para preferir "semiótica de la justicia". Toda una justificación al respecto hemos venido labrando, no la citamos pues la obra respectiva no se encuentra publicada en el momento de concluir este texto. No obstante, adelantamos que la nomenclatura "semiótica de la justicia", parece favorable a vincular la participación de los legos del Derecho en los procesos de construcción y transmisión del sentido de justicia. Lo que al menos parece menos claro en las otras dos expresiones, en la medida que sugieren una comunidad de hablantes especializada. 
sugerida consigo mismo no es explicable mediante la teoría del signo. Dicha teoría está dispuesta nada más que para poder ver los signos que sirven para construir e intercambiar sentido con alguien más mediante actos de habla. El signo es sagradamente social; luego, signos, comunicación y sentido son aspectos de una misma óntica.

Entonces, que haya habido un momento -más extenso de lo debido quizás, en que se pretendió reducir la semiótica al estudio de los signos, no es sino una episteme que los privilegia, caracterizada precisamente por reducir y acaso subordinar al estudio de los signos, los procesos comunicativos al tiempo que desentenderse del sentido, cuando no reducirlo a su nuda enunciación.

El porqué haya sido así pudo haber obedecido a una estrategia, a un accidente o a una verdadera convicción, es algo que no es muy claro. Por ello preferimos denominarlo vicisitud ${ }^{9}$.

Decíamos que estamos describiendo algo historiográficamente identificable de la semiótica, pero también que la cuestionamos, pues encontramos en ella una especie de impostación, no solo incómoda sino también ilusoria.

Con decisión e insistencia nos manifestamos en contra, pues si bien no desapercibimos que en alguna forma la tendencia sigue manifestándose, tampoco puede en la actualidad desatenderse que signos, comunicación y sentido son aspectos del mismo fenómeno, y que hacer prevalecer alguno sobre el otro no desmiente los restantes, aun cuando los deja latentes. Así como otorgarle más importancia al cerebro y al corazón humano por parte de la medicina, no hace que la vida de un ser sea menos importante frente a dichos órganos ${ }^{10}$.

Siguen siendo unidad pese a la especialización de las investigaciones, según inclinen su preferencia por alguna de las tres manifestaciones del objeto de la semiótica, discernimiento que ha favorecido la indeterminación y a la medianía respecto de otros saberes, lo cual han sabido capitalizar los antisemiotistas, por cierto ${ }^{11}$.

9 Algo similar ha sucedido con la retórica, pues en momentos dados se ha privilegiado la elocutio sobre la inventio y la dispositio. Para una apreciación historiográfica de la semiótica y su estatuto científico véase, Castañares, Wenceslao (2014). Historia del pensamiento semiótico. Madrid: Trotta, v. 1, 2 y 3.

10 Incluso creemos que la confusión y hasta la disputa que se ha formulado entre la hermenéutica contextual y la semiótica proviene de haber creído que el estatuto científico de la semiótica no es otro que los sistemas de signos. Así por ejemplo, si Ricoeur hubiese estimado que además de los sistemas de signos participan los procesos comunicativos y muy especialmente el sentido, no hubiese tenido la necesidad de tratar de justificar la preeminencia de la hermenéutica sobre la semiótica, pues creyó que la primera por contextualización rescataba la comunicación y el sentido. RicoeUR, PAUL (1990). Between Hermeneutics and Semiotics. International Journal for the Semiotics of Law. Volume 3, Issue 2: pp. 115-132.

11 Eco, Umberto (1991). Tratado de Semiótica General, Barcelona. Editorial Lumen. Quinta edición. 
Insistimos en que pese a todo se trata de un mismo objeto que puede especificarse de tres formas - si se quiere, distintas ${ }^{12}$. Y nos atrevemos a observar que en algunas investigaciones hemos sido quienes se ocupan más del sentido, pero no porque se quiera identificar semiótica con sentido, sino porque ha sido la expresión menos trabajada y, en busca de la debida compensación entre los tres, nuestro aporte ha sido el desarrollo de la teoría del sentido. Por supuesto, nos servimos de los ingentes avances que particularmente en materia de signos han aportado los grandes semiotistas.

Eso sí, nada nos hace declinar que el sentido carece de sentido sin los signos y los procesos comunicativos.

Entonces la semiótica en general se ocupa de esas tres manifestaciones de la vida de los seres humanos, lo que permite denotar que la semiótica jurídica tiene por objeto los signos, la comunicación y el sentido del Derecho ${ }^{13}$. Y ningún investigador que proceda mediante el método semiótico debía permitirse indulgencias dispuestas a justificar la minimización de alguno de los aspectos del objeto científico, tal y como sucede con la semiótica jurídica que ha venido prefiriendo el estudio de los textos jurídicos, al descuido de los demás signos y del sentido del Derecho, lo cual se traduce de facto en nada más que iurislisgüística ${ }^{14}$. Por demás, esta reducción tan habitual a los semiotistas del Derecho ha sido peligrosamente favorable a crear la confusión respecto de la sociología del Derecho y, con ello el estancamiento del desarrollo de la semiótica, muy acentuado a nivel de Iberoamérica ${ }^{15}$.

Nos aproximaremos cómodamente a los tres, con el fin de describir brevemente el método de la semiótica, pero debemos observar que no por preferencia sino por necesidad de comprensión, procuraremos descubrir nuestros aportes a la teoría del sentido de la justicia.

12 Así, por ejemplo, en Greimas y Fontanille (1994). Semiótica de las pasiones. De los estados de cosas a los estados de ánimo, trad. Gabriel Hernández Aguilar y Roberto Flórez, México: Siglo XXI Editores, segunda edición, pp. 21-95, parece acentuarse más el sentido sobre los signos y los procesos comunicativos.

13 WERnER, WOUTER G. (1995). Legal signs and legal science. International Journal for the Semiotics of Law. Volume 8, Issue 2: pp. 207-218.

14 Por cierto, la reducción que observamos a la semiótica del Derecho nos evoca de inmediato la disputa entre los límites de la semiótica y la lingüística a propósito de los trabajos de Louis Hjelmslev y de Saussure.

15 Quizás obedezca a la tendencia heredada de trabajos como los de KALINOSwsKi, GEORGES (1975). Lógica del Discurso Normativo, Madrid: Tecnos, o de LANDOwSKi, ERIC (1973). La Sociedad Figurada: Ensayos de Sociosemiótica, México: Univ. Autónoma de Puebla: Fondo de Cultura Económica. En estas obras no descubrimos un error, sino una episteme adecuada a un momento histórico en que del estatuto científico de la semiótica, se sobrepusieron los signos a las comunicaciones y al sentido. Pero en la actualidad el desafío científico consiste en conservar el equilibrio de los tres aspectos del objeto de conocimiento de la semiótica en general, y de la semiótica jurídica en particular, al respecto encontramos una tendencia faorable en trabajos como el de Barranco, Graciela De Busaniche (1988). La retórica de los interpretantes Ch. S. Peirce. Cuadernos Gritex, 1988. 


\section{INTRODUCCIÓN AL SIGNO JURÍDICO Y A LA COMUNICACIÓN EN EL DERECHO}

Como base de partida, podemos denotar que un signo jurídico es todo aquello que sirve a re-presentar lo que es jurídico y también el objeto de su némesis, en su justificación subyacente y pisque el sistema social que es, al cabo, su objeto de venganza. Es decir, todo aquello que desafía el estatus quo con cierto tipo de riesgo, en el metalenguaje jurídico-penal diríamos antijuridicidad.

La representación es una función que consiste en transferir la experiencia que podría suscitar en el sujeto un objeto ónticamente ausente. Pero no se trata de una ausencia como tradicionalmente es entendida, pues si bien el objeto referido no está presente, la magia del signo consiste en que al remitir a él propicia la experiencia de su presencia. De esa forma, aquello que es representado puede decir algo, no solo mediante su silencio sino también a condición de no estar presente.

Si bien la capacidad de poderse comunicar en tales condiciones no sea totalmente exclusiva del ser humano, la semiosis como tal es posible nada más que en las comunidades humanas, las cuales han constituido su modelo social basado en las representaciones y las creencias en las mismas, tal y como ha sido postulado desde Platón hasta Habermas, desde Husserl y Shûtz hasta Searle. Al menos podemos afirmar que establecer procesos comunicativos de cierta complejidad tal y como lo hacen las comunidades de hablantes humanos, parece más que inalcanzable, relativo a otras criaturas ${ }^{16}$.

En general, el signo se ha entendido como una relación entre algo representado, también conocido como referente ([]), un representamen o significante (//) y, un significado $(« »)^{17}$. Curiosamente la representación termina siendo tanto o más poderosa que el mismo referente, de ahí que se insista en la idea de la construcción

16 Sabemos que hay procesos comunicativos entre muchos animales, pero lo que no creemos o al menos carecemos de razones para aceptarlo es que requieran, como lo precisa un ser humano, de hacer presa del mundo mediante la semiosis. Es decir, la complejidad semiótica de las comunidades humanas no es solo una cuestión de vida o muerte física, sino de vida o muerte espiritual, de su propia identidad como ser. Al fin y al cabo, un ser humano precisa hacer del mundo su propio mundo, como lo dijera Merleau-Ponty, pues su relación original con él no es de unidad sino de encuentro. Que se sepa sobre ningún otro animal pesa semejante carga y, por lo mismo la pisque humana es la más compleja.

17 Peirce agregó la idea del interpretante, PeIrCe, Charles (2008). El pragmatismo, trad. Sara Barrena, Madrid: Ediciones Encuentro, S.A., donde define el signo como "algo, de cualquier modo de ser, que media entre un objeto y un interpretante, ya que es determinado por el objeto en relación al interpretante, y determina a su vez al interpretante en referencia al objeto, de tal modo como para hacer que le interpretante sea determinado por el objeto a través de la mediación de ese «signo»" (p. 84). Se aprecia que en su obra la concepción tríada del interpretante (energético, emocional y conceptual), termina siendo aquello que permite hacer algo con los signos, tal vez una modificación de la conciencia (pp. 124-130). Por ello mantenemos que su concepción del interpretante tiene más que ver con el sentido que con el mismo signo. 
social de la realidad, y es indiscutible que la representación termina siendo la misma realidad de las comunidades de hablantes, lo cual es profundamente cierto respecto de la iusphera, es decir, del lugar social en donde sucede la semiosis del Derecho.

Ahora bien, la razón de ser del signo es servir de precursor a la comunicación y al sentido, ya que por su propia naturaleza el signo es una unidad cuya función consiste en servir a la comunicación. Es de esta entidad las funciones que cumple, la comunicación es la contigüidad del signo ${ }^{18}$.

Sobre ella es bastante conocido el esquema de Jakobson ${ }^{19}$, muy didáctico pero de un acusado reduccionismo y simplificación extremas, conforme al cual es un mecanismo de intercambio de información entre dos interlocutores, válidos de un canal por el cual circula el mensaje, conforme a un contexto dentro del cual se halla el referente comunciativo. Preferimos referir la comunicación como un complejo proceso de actos de habla, operado mediante el uso de sistemas de signos, a través de los cuales se construye el sentido del cual participan los hablantes, o se transmite uno preexistente. Luego podemos sintetizar diciendo que se trata de un proceso de construcción y transmisión de sentido.

El Derecho se ha servido de una multiplicidad de canales, entre ellos el judicial, el legislativo, el académico y, muy especialmente, el canal social. Este último es el más crítico en cuanto es el más acudido por la sociedad, aun cuando puede ser el menos sonoro, el menos escandaloso si se quiere. Pero no deja de ser allí donde sucede la mayor parte de los procesos comunicativos del Derecho, y por lo mismo es donde se engendra el sentido social de justicia. Se trata de las relaciones humanas de contenido jurídico que hacen parte de la vida del sistema social en el silencio de sus funciones, es el suceder cotidiano, permanente y rico de los actos jurídicos del acontecer cotidiano de las personas, así como la compra y el transporte de la comida, el trabajo, la prestación de servicios domiciliarios, personales, etc. ${ }^{20}$.

La tradición ha preferido, no obstante, las comunicaciones jurídicas más ruidosas y agresivas, es decir, las judiciales, pese a ser relativamente menos en cuanto a su número y, en todo caso, sospechosas en relación a su incidencia en la construcción del sentido de justicia, pues parece ser que la relación es más bien invertida, es decir, reciben y transmiten un sentido que las precede, pero no es muy claro si realmente

18 Izzo, Valerio N. (2012). Beyond Consensus: Law, Disagreement and Democracy. International Journal for the Semiotics of Law. Volume 25, Issue 4: pp. 563-575.

19 Jakobson, Roman (1996). El Marco del Lenguaje. México: Fondo de Cultura Económica.

20 CARnera, AlexÁNDER (2012). Freedom of Speech as an Expressive Mode of Existence. International Journal for the Semiotics of Law. Volume 25, Issue1: pp. 57-69. 
crean justicia entendida como sentido, y el efecto que tendría sobre las restantes operaciones comunicativas ${ }^{21}$.

El Derecho, más precisamente la justicia, es un fenómeno social que en tanto tal es a condición de ser comunicado. Como lo dijera Lacan respecto del ser, la justicia es hablada y, al igual que todo lo concerniente a la sociedad humana, no es concebible sin esos actos de habla que llamamos comunicación, pues comunicándose es que surge su propia realidad, luego comunicarse es el ser en sí de las comunidades humanas ${ }^{22}$.

Confiamos en que se aclare un poco más lo artificial y nada ortopédico de las reducciones, sea en semiótica general o en semiótica jurídica en particular, pues si los sistemas de signos se explican porque sirven a la comunicación y esta a su vez es producción y transmisión de sentido, los tres no son sino aspectos de lo mismo. Apenas pueden ser alternativas de encuentro, pero siempre en razón de la misma unidad. De donde insistamos en lo inescindible del objeto de conocimiento ${ }^{23}$.

\section{HACIA UNA TEORÍA DEL SENTIDO DEL DERECHO}

El que pueda deducirse en esta investigación una cierta preferencia por el sentido se explica, como lo dijimos, por haber hallado que se trata de lo más inaprehensible y evitado por los semiotistas, quienes han tenido históricamente una marcada inclinación hacia los signos y eventualmente por la comunicación -no desconocemos que de la misma se han venido ocupando cada vez más los sociólogos. Lo cual contrasta con la trascendencia del sentido, por cierto, más clara a los literatos que a los mismos semiotistas: "Morirás por el sentido del libro, no por la tinta ni el papel", dijo sabiamente de Saint-Exupéry ${ }^{24}$.

No perdemos de vista que el sentido es una posibilidad de dar inicio al abordaje de un objeto de conocimiento del cual los signos y la comunicación son otras posibili-

21 Repetidamente hemos señalado que sociólogos como Bourdieu al identificar el campo jurídico con el espacio judicial, han privado sus modelos teóricos de un verdadero encuentro con el sentido de justicia. Pues lo que hallamos semióticamente es que ese sentido proviene de la sociedad y que los administradores de justicia tienden a realizarlo. Pero que lo contrario, es decir, que los expertos en Derecho pauten a la sociedad ese sentido, solo tiene posibilidad cuando el dictado corresponde a un sentido de justicia preexistente. El curso observado es el primero, es decir, una sociedad crea su propio sentido de justicia, y cuando mediante una sentencia o una institución se proyectan en contradicción, va surgiendo la violencia social.

22 SHÜTZ,AlFRED (1966). Fenomenología del Mundo Social. Introducción a la Sociología Comprensiva, Barcelona: Paidós.

23 Van Den Hoven, Paul (1988). Legal argumentation as an illocutionary act complex: A critical analysis. International Journal for the Semiotics of Law. Volume, Issue 11: pp. 29-45.

24 De Saint-Exupéry, Antoine (1998). Ciudadela, trad. Hellen Ferro, Barcelona: Alba Editorial, S.L., segunda edición, pp. 410. 
dades. Lo importante es no discernirlos, es no ignorar alguno, sino en cambio dejar intacta la unidad.

Recurrentemente hemos expuesto -y anticipamos que la repetición no es ningún "autoplagio" sino una estrategia de reflexión-, que el sentido -a la manera de Frege-puede comprenderse no tanto partiendo de precisiones sino de las confusiones creadas respecto de él ${ }^{25}$.

Es así que seguimos sosteniendo que no es significación ${ }^{26}$, por lo mismo es que no aventuraríamos que pueda tratarse de la semántica de los textos ${ }^{27}$.

Por ejemplo, decir /hombre negro/ significa «ser humano masculino de raza negra», pero el sentido compromete aspectos sociales que escapan al significado, y de ello dependen lo usos del mismo. Quiérase o no, nunca ha sido igual referirse a un / hombre negro/ respecto de Estados Unidos en la época de Luther King, que referirse a un sudafricano de raza negra que habita en Pretoria, así estemos hablando de la misma época.

La explicación es que el sentido es metasemántico, pues se descubre más allá de la racionalidad de la semántica, al tiempo que compromete las convergencias culturales de una comunidad ${ }^{28}$. Por ello abriga lo racional como lo irracional, lo que es y lo que no es. En el sentido se encuentran sin prejuicio lo que racionalmente corresponde a las categorías de falso y verdadero, de lo que es y lo que no es. Hay tantas y buenas verdades respecto de lo mismo en el sentido, que ir a él en la nave de la lógica formal asegura un desconsolador accidente.

25 Se asigna este discernimiento a Frege, cuyas ideas lingüísticas resultan propicias y afines a los fundamentos de la semiótica. Cfr. Von Kutschera, Franz (1979). Filosofía del lenguaje, trad. Adelino Álvarez, Madrid: Gredos, pp. 60-70.

26 Esto es precisamente lo que se aprecia en BARTHES, Roland (2010). Mitologías, trad. Héctor Schmucler. México: Siglo XxI. "La significación es el mito mismo” (p. 213) afirmó, y redondeó su idea: “... el significante tiene en cierto modo dos caras: una cara llena que es el sentido... y una cara vacía que es la forma... lo que el concepto deforma es la cara llena, el sentido..." (p. 214).

27 Tal vez convenga aclarar que más que una coincidencia se trata de una relación, conforme con la cual la ausencia de significado conlleva la ausencia de sentido, tal y como lo sostuvo WITTGENSTEIN, LudwIG (2002). Tractatus Logico-Philosophicus, trad. Luis Valdés Villanueva, Madrid: Tecnos, edición 3, para quien "cualquier proposición legítimamente formada tiene que tener un sentido; y si no tiene, esto solo puede ser consecuencia de que no hemos dado un significado a alguna de sus partes constituyentes. Así pues, «Sócrates es idéntico» no dice nada porque no hemos dado a la palabra «idéntico» ningún significado como adjetivo". (5.4733)

28 Luhmann, Niklas (2005). El Derecho de la sociedad, trad. Rafael Torres Nafarrate, México: Herder, pp. 276 y 380. De hecho coincide con la idea de que la escritura realiza mucho más de lo que expresa. Cfr. Kevelson, Roberta (1987). Charles S. Peirce Method of Methods, Amsterdam; Philadelphia: John Benjamins Publishing. 
Para asir el sentido es inevitable despojarse de cualquier saber, de cualquier prejuicio, de todo preconcepto. Tal vez esa condición haga tan inaprehensible el llamado sentido común, y se haya preferido reservarlo a las minorías que, en todo caso, tampoco logran dar cuenta de él.

Nos hemos valido de Merleau Ponty para explicar el porqué así como el sentido no se explica por los significados, tampoco mediante la idea tan sagrada a la filosofía, de la esencialidad:

Nada nos autoriza a decir que las esencias que encontramos le dan al Ser su sentido primitivo, que son lo posible en sí, todo lo posible, que lo que no obedece a su leyes es imposible y que el Ser y el mundo son sus consecuencias; en realidad, solo son su modo de ser, su estilo, el Sosein y no el Sein, y si podemos decir con fundamento que todo pensamiento las respeta, como las respeta el nuestro, si tienen valor universal, es únicamente en cuanto otro pensamiento fundado en otros principios, para darse a conocer a nosotros, para entrar en comunicación con nosotros, tendría que presentarse a las condiciones del nuestro, de nuestra experiencia, y ocupar un sitio en nuestro mundo, y porque, en definitiva, todo pensante $u$ toda esencia posible se refieren a una única experiencia y a un mismo mundo ${ }^{29}$.

Puede que la única experiencia y por ello esencia a la que puede referirse el /ser mujer/ converja en la maternidad. Pero el sentido que adquiere no se identifica con dicha convergencia, por ejemplo, no es igual la Virgen María representada por la iglesia Católica, que las de iglesias cristianas. Diferencia persistente pese al vínculo manifiesto, esencial y compartido respecto de la maternidad de Jesús ${ }^{30}$. Obsérvese que en tanto signo comparten el mismo referente y el mismo significado, en esencia se trata del mismo ser.

Pero es irreductible que el sentido construido en cada uno de esos contextos resulta acentuadamente distinto.

Por otro lado, sentido y orientación han sido frecuentemente asimilados, pero cuidadosamente atendidos, la diferencia es inobjetable ${ }^{31}$. Para ello nos servimos de la

29 Merleau-Ponty, Maurice (1970). Lo visible y lo invisible, trad. José Escudé, Barcelona: Editorial Seix Barral, S.A., pp. 140

30 A diferencia de las iglesias cristianas - al menos la mayoría conocida-, la Iglesia Católica diviniza a la Virgen María, siendo un símbolo de pureza, de sacrificio silencioso, de entrega humilde a la voluntad de Dios.

31 Al respecto, algunas comunidades construyen una especie de sinécdoque valiéndose de un "pseudosinonimia", usando la palabra sentido como si fuera orientación: "vaya en sentido norte". No obstante el sentido de "norte" puede ser el de razón de ser de alguien, de destino o de realización, como cuando alguien dice "mi norte eres tú". 
relación "intencionalidad-intensionalidad", derivando que la orientación tiene que ver con la intencionalidad, mientras que el sentido más con la intencionalidad ${ }^{32}$.

Puesto que intencionalmente se vincula el uso de un signo con un cierto significado, intensionalmente es despojado de otros probables significados y, por ello mismo, contribuye a las opciones de sentido. Por ello es que la intensionalidad tiene que ver con los límites extensionales de significación probable.

Así es que intencionalmente se puede forjar un vínculo semántico entre /democracia/ y "gobierno por mayorías". Pero intencionalmente puede resultar asociada a la exclusión de mayorías divididas y derrotadas por las minorías mejor organizadas. Con ello propiciar el sentido de irrealidad de la democracia, o la ironía de su declarada apetencia.

Entonces, si la intencionalidad compromete un significado, y sentido y significado son dos cosas distintas -cuando no opuestas-, mientras que la intensionalidad lía todo lo contrario, es decir, lo que no se quiere significar, pero sí precisa lo que se quiere transmitir, inevitablemente el sentido debe rastrearse por este lado.

Ahora bien, lo anterior puede sugerir un equívoco al que queremos anticipar. Se trata de asociar el sentido con las representaciones sociales, lo cual lo hemos encontrado también como un extravío, al menos de la forma como tradicionalmente son vinculados. Nos explicamos con el siguiente ejemplo: una sociedad puede representar la pobreza como un problema social, en el que las personas que adquieren la condición sígnica de "pobres" son víctimas sociales.

Pero el sentido de la pobreza puede ser otro, por ejemplo, la condición o antesala de la salvación dentro del contexto de la resurrección en una dimensión suprahumana.

No obstante, admitimos que podría oponerse el tratarse, en todo caso, de una representación. Y puede que haya mucho de cierto, pero lo que hemos encontrado es que las representaciones que explican el sentido se caracterizan por unas condiciones especiales que se revelan en complejidad, de donde suelan ser más sutiles y frecuentemente difíciles de asir.

Quizás la principal característica consista en que se respaldan más en el conocimiento abductivo que en el lógico-formal, pues la sociedad experimenta algo de lo cual deduce la hipótesis a la cual corresponde, y lo experimenta como su demostración. La hipótesis es erigida en lo que Peirce llamó interpretante. La inmediatez de la que surge compromete tanto y al mismo tiempo la razón y la sinrazón, el instinto, la experiencia y el presentimiento, entre otros, y por ello de él participa tanto lo que es

32 Greimas y COURTES (1991), pp. 372-373. 
una comunidad como lo que quiere ser, luego en él hay tanto de cierto como de no cierto -aristotélicamente hablando ${ }^{33}$.

Entonces, a esas representaciones que se forjan predominantemente mediante abducción, y que no son las representaciones tradicionalmente entendidas, es lo que hemos preferimos denominar metarrepresentaciones ${ }^{34}$.

Nos valemos del mismo ejemplo surgido de una investigación porque a nuestro juicio hizo emerger una metarrepresentación, figura sin la cual no sería visible ni explicable el fenómeno.

Se trató del delito de inasistencia alimentaria en Colombia, y la práctica judicial en relación con el mismo ${ }^{35}$. Para entenderlo debemos observar que como en la actualidad, cuando se hizo la investigación Colombia lo registraba dentro del grupo los cinco de más alta frecuencia, es decir, junto con los delitos contra el patrimonio y la integridad física. Es importante señalar que, en general, según los registros de Naciones Unidas, estos últimos son de alta frecuencia en casi todo el mundo, pero no pasa lo mismo con la inasistencia alimentaria, pues Colombia es el único país que lo aparejaba en términos de alta ocurrencia.

Lo que encontramos es que las sentencias condenatorias correspondían con esas frecuencias. Pero al estudiar los casos se encontró que en la mayor parte las personas fueron condenadas sin que las instancias judiciales respectivas y comprometidas con la aplicación de la ley penal se hayan sujetado a sus exigencias, por suerte que de haberles sido garantizado su aplicación integral el resultado es que habrían sido absueltas. Es decir, desde una perspectiva hermenéutica y dogmática, la conclusión fue que en la mayoría de los procesos se habían violado los principios de tipicidad, de antijuridicidad y de culpabilidad.

Por supuesto, concluir que se trataba de un caso crítico de anomia judicial, era lo máximo que la sociología jurídica podía ofrecer. Pero la semiótica jurídica, aun cuando podía servirse de los resultados señalados, le resultaban bastante pobres.

33 Puerto, César Fredy Pongutá (2015). Charles Sanders Peirce: conmemorativo en el centenario de su muerte. Cuadernos de Filosofía Latinoamericana, vol. 35, no 111, pp. 13-29.

34 Si las expresiones han sido acuñadas por otros investigadores en otros textos, lo ignoramos. Puede parecer la propuesta de neologismos que al parecer tienen mucho que ver con lo que en HaLLIDAY, Michael (1994). El lenguaje como semiótica social. La interpretación social del lenguaje y del significado, trad. Jorge Ferreiro Santana, Santafé de Bogotá: Fondo de Cultura Económica Ltda., se lee como "algún nivel superior de significado extralingüístico" (pp. 106).

35 Moya Vargas, Manuel Fernando (2007). Los Fallos Penales por Inasistencia Alimentaria: un desfase entre la ley y la práctica judicial, Bogotá: Universidad Santo Tomás. 
Pues bien, conforme con ella y a partir de ella, el fenómeno no consiste apenas en que se violen de semejante forma los principios más sagrados al Derecho y al sistema penal, al menos desde hace dos siglos. Sino que pese a eso no suceda absolutamente nada. Obsérvese que si el Estado reconocía la frecuencia nada despreciable de un comportamiento que afecta la familia, en la dogmática penal colombiana uno de los más distinguidos bienes jurídicos, el mismo que "parsonianamente" fue erigido en fundamento social conforme a la Constitución de 1991, ¿cómo era posible que contrario a lo que sucedía con los delitos contra el patrimonio y la integridad no se hubiese hecho absolutamente nada para al menos comprenderlo? Ahora, si es que se era conscientes de la violación a la Constitución y a la ley penal por parte de los administradores de justicia, ¿no era acaso algo muchísimo más grave y reclamaba reacciones así fuesen inmediatas y a corto plazo?

Al fin y al cabo, el fenómeno de la inasistencia alimentaria no es apenas una cuestión de inaplicación de la ley penal y de la violación de toda la racionalidad hermenéutica en que se soporta, pues no hay -ni entonces ni ahora- políticas públicas de reducción de la supuesta frecuencia delictiva, pese a atacar un bien jurídico constitucionalmente erigido y fundamental a la sociedad. Lo cual pareciera deber urgir aún más al Estado, teniendo en cuenta que la población carcelaria se incrementa significativamente con los condenados por inasistencia alimentaria, en un país que padece quizás el peor hacinamiento carcelario del mundo ${ }^{36}$.

En una frase, lo absurdo de la situación queda claro: a una probable anomia social (la recurrencia de la inasistencia alimentaria), se responde con una segunda anomia judicial (la violación de la ley penal) y, finalmente frente a ninguna de las dos el Estado, la sociedad y nadie reaccionan. Aquí no hay argumento, ni silogismo, nada que la lógica permita comprender.

Lo que evidenció la investigación semiótica es que las cosas son así como consecuencia del sentido de justicia latente en las sentencias, el cual proviene no de la lógica jurídica ni del discurso del Derecho sino del encuentro de las metarrepresentaciones sociales de lo que es ser un buen padre, una buena madre y un hijo, profundamente vinculadas a la aculturación cristiana que se desató con la conquista.

De esa forma, mediante las sentencias que, al cabo no verificaban la existencia penal de las omisiones acusadas ni mucho menos resolvían el problema social que se presentaba a las oficinas judiciales, sino que, al contrario, lo profundizaban. Más aún si era verdaderamente inexistente, ahora se convertía en algo real. Pero así se lograba materializar un sentido social de justicia a partir del cual debe castigarse con toda la severidad posible a los hombres -más del $90 \%$ de los condenados eran hombres y lo siguen siendo hoy- que hubiesen tenido el arrojo de tener hijos, pues no solo

36 Colombia, Corte Constitucional, Sentencias T-153 de 1998, T-388 de 2013 y T-762 de 2015. 
lo victimizaban a él -aun cuando el hijo era lo que menos importaba en la sentencia-, pues proporcionarle medios de subsistencia no hacía parte de la construcción de la sentencia, y no menos a la madre, incluso otros familiares que venían a suplir al padre de una u otra forma, por las cuales no estaban dispuestos a sacrificarse así fuese en contra de su propia vida, sin importar que pudieran o no responder por ellos.

Poco o nada importan lo sensato o insensato de ese sentido, lo cierto es que lo forjó una sociedad que cree que un buen padre es el padre sacrificado, al cual llama "papá responsable". Esa es una metarrepresentación, que confluye en castigar al hombre que la defrauda, así sea a expensas de la propia historia del Derecho penal. Y creemos que la hipótesis abductiva tuvo por origen óntico y experiencial, la relación descrita en el antiguo testamento entre Dios y sus hijos de Israel, esto es, entre el Señor y sus siervos.

Insistimos en que la metarrepresentación procede de saberes típicamente abductivos, mientras que las representaciones ordinarias suelen ser deliberadas, como quiera que en algún punto o extremo de la relación, ha sido promovida a fin de concretarla, tal y como sucede con los hechos institucionales.

Las representaciones sociales constituyen el contexto esencial de las comunicaciones, y por ello suelen ser reconocidas o reconocibles por los hablantes. Suelen responder a las llamadas "frases de cajón", por ejemplo, "hasta los animales alimentan a sus hijos", "si tiene para beber por qué no para darle de comer a sus hijos" o "si fue capaz de engendrarlo tendrá que alimentarlo".

En cambio, las metarrepresentaciones subyacen al sentido, pese a que no necesariamente -y tal vez en la mayoría de los casos- la misma sociedad carece de conciencia acerca de su vigencia y contenido, les basta su silencio, lo cual facilita ser portadas por las comunidades cuya personalidad está siempre invadida por ellas ${ }^{37}$.

Su lugar es la dimensión social donde desembocan las antinomias sociales, por encontrarnos principios-contraprincipios, valores-contravalores, deseos-repudios, presencias-indiferencias, etc., todos tan importantes como puedan ser reales e irreales al mismo tiempo.

Hemos sostenido que si los procesos sociales se consideran a partir de las metarrepresentaciones, la historia puede ofrecer lecciones mucho más edificantes y preventivas ${ }^{38}$.

37 Tenemos razones para creer que se trata de lo que Husserl y Marleau-Ponty llamaron "tomas de situación".

38 En el caso citado de la inasistencia alimentaria, pudimos señalar que la situación describía un círculo vicioso bastante propicio a un drama social que, indudablemente, desembocaba en mayores índices de violencia, de inseguridad, en fin, de condiciones de vida indignas. Precisamente si se condena a unas personas respecto de las cuales no se tiene certeza de la responsabilidad, sino a partir de la 
Podríamos ahora precisar que el elemento del sentido son las metarrepresentaciones, es decir, el sentido es un encuentro de materrepresentaciones. Se trata de lo que con ellas puede hacerse mediante los actos de habla. Y ese ajuste de la conciencia que sucede como consecuencia de la reafirmación o cambio de sentido es lo que a su vez llamamos actos de habla metalocucionarios. De donde hemos sostenido que el sentido no solo tiene efectos actitudinales, sino actualizaciones de creencias mediante tomas de situación.

Al respecto encontramos que Husserl apuntó en la misma dirección, al explicarlo mediante la dinámica noema-noesis:

Toda vivencia intencional es, gracias a sus momentos noéticos, precisamente noética; es su esencia albergar en sí algo así como un "sentido", y eventualmente un múltiple sentido, llevar a cabo sobre la base de estas daciones de sentido y a una con ellas nuevas operaciones que por ella resultan precisamente "llenas de sentido". Momentos noéticos semejantes son, por ejemplo: direcciones de la mirada del yo puro al objeto "mentado" por él en virtud de la dación de sentido, al objeto que "tiene en mente"; además, captación de ese objeto, sujeción del mismo mientras la mirada se vuelve a otros objetos que han entrado en el "mentar"; igualmente operaciones/del explicita, del referir, del asir reunidos, de las variadas tomas de posición del creer, conjeturar, del valorar, etc. Todo esto cabe encontrar en las respectivas vivencias, por variada que sea su estructura y por mudables que sean en sí. Pero por mucho que esta serie de ejemplos de momentos apunte a componentes efectivamente ingredientes de las vivencias, lo cierto es que también remite, por medio del título "sentido", a componentes NO A INGREDIENTES ${ }^{39}$.

Ciertamente la oposición noema-noesis y con ella la de noético-noemático, concluye en la aproximación al sentido en función de las metarrepresentaciones. Pues las ver-

condición nuda del ser padres, no solo no se soluciona el problema real del acreedor alimentario sino que, al emerger un deudor individual mediante la sentencia, ya hay un responsable, y de ese modo nadie pasa a sustituirlo, ni mucho menos a solucionar ese problema real. Tenemos razones para concluir que ese trabajo sirvió para que en Colombia, mediante el llamado Código de Infancia y Adolescencia o Ley 1098 de 2006, haya erigido el llamado principio de corresponsabilidad respecto de los menores entre familia-sociedad-Estado. Pero el mismo principio, lo decimos ahora, se puede fracturar si hay un falso deudor de alimentos, prueba de lo cual es que no se ha implementado al forma de hacerlo valer. Lo cierto es que con o sin responsables, lo que se precisa es implementar un método de atención a las personas que no pueden atender sus necesidades vitales, pues el asunto no es tanto buscar castigos, como encontrar soluciones. Sigue valiendo la metarrepresentación de los buenos padres, pero debe darse lugar a la correspondiente e un buen Estado.

39 HuSSERL, EDMUNDO (2013). Ideas relativas a una fenomenología pura y a una filosofía fenomenológica. Libro primero: introducción general a la fenomenología pura, trad. José Gaos, edición y refundición por Antonio Zirión Quijano, México: Fondo de Cultura Económica, pp. 293-294. 
siones noéticas no son sino las distintas perspectivas de sentido que puede adquirir la versión noemática de los fenómenos.

Algo que importa destacar ahora es que el sentido y los signos no son un epistemológicamente subjetivo para sí. Se trascienden a sí mismos en la medida en que ser compartidos por una comunidad de hablantes hace parte de su esencia: "Si te gusta conocer la aventura de otro para acrecentar la tuya -pues entonces adquiere un sentido- vas a golpear a la puerta de un amigo" 40 .

Por ello mismo la antropología que resignifica la "cultura" confluye en algo similar" pues la define como sentido compartido ${ }^{42}$. Lo cual explica que una práctica ilegal y hasta ilícita pueda sostenerse aun contra otro tipo de interés, en la medida en que acoja el sentido social, y se transfigure en lo que llamamos justicia, que es el sentido puro del Derecho, empleado por la sociedad a través de las oficinas judiciales ${ }^{43}$.

El carácter social del sentido es tan inextricable como inevitable. De hecho, el sentido se define al igual que los signos, por esa condición. Si no es compartido no puede ser sentido, pues, ¿para qué serviría si no para vincular a la comundiad de hablantes en cuyos procesos comunicativos circula invariablemente? Warley, refiriéndose a Peirce ${ }^{44}$, lo asoció a la vida misma de las comunidades: "En cualquier caso, se trata de la vida de los hombres entendida como ese flujo de sentido que se crea y se recrea y que nunca se detiene" 45 . Cuanto hemos referido de la antropología en términso de cultura, es justamente su descubrimiento en cuanto a que la identidad de una sociedad es el sentido que comparte, manifiesto en sus propias creencias, mucho más allá que las prácticas repetidas.

Pero a los semiotistas obsesionados con los signos les resulta sospechoso, pues no conciben las posibilidades del consenso en que debería soportarse ${ }^{46}$. Curiosamente no advierten que los signos también son compartidos y respecto de ellos no les inquieta tanto el consenso. Lo que podemos advertir es que el consenso social no es

40 De SAINT-Exupéry, ANTOINe (1998), p. 440.

41 LÉvi-Strauss, Claude (1985). Las Estructuras Elementales del Parentesco (II), Barcelona: Planeta Agostini, pp. 555-575. Cfr. Geertz, Clifford (2003). El Surgimiento de la Antropolgía Postmoderna, Barcelona: Gedisa, Cfr.

42 Geertz, Clifford (1987). La Interpretación de las Culturas, Barcelona: Gedisa.

43 VAn Schooten, Hanneke (1996). The meaning of law as instrument. International Journal for the Semiotics of Law. Volume 9, Issue 1: pp. 95-108.

44 El artículo apareció en 1878 en el Popular Science Monthly, bajo el título "How to Make Our Ideas Clear".

45 Warley, Jorge (2007). Semiótica de los Medios. Signo, representación, ideología, política, Buenos Aires: Biblos, pp. 20.

46 Foley, Richard (2002). Convention as Intention - The Institution in All of Us. International Journal for the Semiotics of Law. Volume 15, Issue 4: pp. 431-434. 
un acuerdo irreductible, sino algo a la manera del llamado contrato social que, más que un estar de acuerdo, es un remar en la misma dirección ${ }^{47}$.

El sentido es el precursor de las creencias sociales y, por ello mismo, de la realidad social. Pues, ¿cómo creer en la institución del dinero sin que provenga de un sentido que correlaciona la metarrepresentación de la riqueza y su flujo, con la metarrepresentación de la comodidad implícita en la fungibilidad de la satisfacción supraindividual de los requerimientos individuales?

Tal vez a la teoría de Searle, con la cual nos identificamos, contribuya una teoría del sentido tal y como la formulamos ${ }^{48}$. Pues si bien compartimos que institución alguna funcionaría sin la respectiva creencia social de respaldo, tenemos que preguntarnos ¿qué es lo que hace probable que una sociedad crea en un hecho que pretende ser institucional? Por supuesto la fórmula X cuenta como Y en C, describe una realidad institucional, pero no el proceso de cómo llega a serlo. Sociedad alguna cede en términos de creencia a una propuesta, o constituye una creencia, sino a condición de surgir del sentido que la preexiste, y de ello dan sobrada cuenta las instituciones jurídicas.

Tan inconclusa es esta condición que cuando una sociedad es violentada mediante una institución inconsulta de su sentido, no tiene otra opción que los procesos de individuación, y de no ajustarse a ellos cae en la más absoluta desuetud. De hecho, es más probable que una institución termine siendo contraria a su propia naturaleza por individuación, a que logre imponerse y ser ella misma fuente de sentido ${ }^{49}$.

En cuanto el sentido circula a través de los actos de habla, es allí donde debe buscarse. Pero es preciso advertir que en la complejidad de dichos actos los signos jurídicos y las narrativas que se construyen con ellos son elementos que no dan cuenta de otros no menos importantes, como la relación entre los hablantes, sus estrategias, intereses de instrumentalización, intenciones auténticamente comunicativas, dinámicas intencionales-intencionales en los usos de los signos, etc., ni mucho menos de las metarrepresentaciones. Por lo que reducir la comunicación jurídica a sus expresiones sígnicas es pretender explicar el complejo jurídico mediante iurislisgüística, lo cual no solo desintegra los procesos comunicativos, sino que se desentiende del sentido. Y ello no es semiótica, pues no se desentiende del sentido. Si el ser es hablado, como decía Lacan, ello no consiste en intercambiar palabras, sino sentido pues como

47 Coskun, Deniz (2007). The Linguistic Turn of Social Contract Theory: Ernst Cassirer and the Conditions for the Possibility of a Promise. International Journal for the Semiotics of Law. Volume 20, Issue 2: pp. 129-158.

48 Searle, John (1997). La Construcción Social de la Realidad, Barcelona: Editorial Paidós.

49 Un ejemplo a la vista es la suerte que han venido corriendo los llamados "sistemas acusatorios" en Latinoamérica. Región con un sentido de justicia que erige al juez por encima de las partes, por ser el encargado de acendrar las fórmulas jurídicas que le son propuestas. Esto más que incompatible con los principios acusatorio y adversativo, es su propia negación. 
lo hemos venido sosteniendo, la comunicación es un proceso de transmisión y de creación del sentido; para ser más precisos, diríamos con Merleau Ponty ${ }^{50}$, se trata de una cogitación.

Y si bien los signos en cualquiera de las manifestaciones que registra su taxonomía son precursores del sentido no por ello se hacen sentido, dada la independencia de aquello que lo hace presente a la conciencia ${ }^{51}$.

Ahora bien, el sentido del Derecho es la justicia ${ }^{52}$, y acontece en la iusphera a la cual hemos llamado también "instinto de juridicidad" 53 . Lo que a nuestro juicio corresponde con lo que Searle llamó "trasfondo" 54 , y Luhmann denominó "entorno" 55 . Se trata del conjunto de capacidades antepredicativas que hacen posibles los estados intencionales de función jurídica ${ }^{56}$.

50 Merleu-Ponty, Maurice (1984). Fenomenología de La Percepción, Barcelona: Editorial Planeta Agostini.

51 Discini, Norma (2015). Corpo e Estilo. Brasil: Editorial Contexto.

52 Kevelson, Roberta (2011). The Law as a System of Signs, New York: Editorial Springer. Cfr. HutTon, Christopher (2009). Meaning, Time and the Law: Ex Post and Ex Ante Perspectives. International Journal for the Semiotics of Law. Volme 22, Issue 3: pp. 279-292.

53 Moya Vargas, Manuel Fernando (2007).

54 El filósofo lo ejemplificó así: "Estoy dispuesto a reírme con determinados chistes, pero no con otros; estoy dispuesto a hablar alto hasta cierto punto, pero no hasta cierto otro; estoy dispuesto a mantenerme a cierta distancia de la gente cuando hablo con ellos, pero no a cierta otra distancia. Llamo a todo esto manifestaciones del trasfondo". SEARLE, John (1997). pp. 148.

55 Luhmann, Niklas (2007). La sociedad de la sociedad, México: Herder, pp. 40-55, 737, 762-763.

56 El concepto es desarrollado en un texto que no es posible citar por cuanto no se encuentra publicado, pero podemos decir que se sirve de la definición que trae Searle sobre trasfondo, para significar que el cumplimiento de las funciones jurídicas, que son comunicativas, como cualquier otra función comunicativa, precisa de la existencia de unas condiciones en cuya ausencia no sería posible la comunicación, y que se caracterizan por ser antepredicativas, es decir, no reclaman conciencia ni actitudes intencionales sobre su existencia, simplemente se las da por presentes, pero están porque de otro modo la comunicación sería improbable. Sus deficiencias revelarían deficiencias de dichas condiciones, como cuando uno de los locutores atiende a un sentido totalmente opuesto al que intenta el otro o los otros. Tal vez dichas condiciones sean en grado sumo desconocidas, pero algunas son reveladoras, por ejemplo, la capacidad de escuchar, entender, atender, valorar, etc. Por ejemplo, no sería posible una comunicación mediante la que un locutor se propone incomodar a otro mediante un insulto, si ese otro no puede sentirse insultado con lo dicho por el anterior. Por ejemplo, si el insulto es manifestado en un idioma que desconoce completamente el pretendidamente insultado, y tampoco logra asociar la intención de quien habla a través de las expresiones de su rostro, su cuerpo en general, ni del contexto en que se hallan. El instinto de juridicidad apunta a la existencia de una condiciones que periten a los hablantes catalogar de justo o injusto, jurídico o antijurídico, el referente de la comunicación. La intangibilidad de su existencia no ha impedido la sugerencia de su presencia, pues se advierte sin mayor dificultad que, por ejemplo, cuando alguien sube a un taxi debe pagar como contraprestación una cierta suma y, que no hacerlo está "mal". Con todo no precisa para ello saber absolutamente nada acerca de los contratos sinalagmáticos, ni de las características del contrato de transporte. Así como cuando se hace daño en el cuerpo de otro, poco o nada se precisa saber del 
Es un ambiente, si se quiere, una dimensión de juridicidad, que toma el saber abductivo de donde provienen las metarrepresentaciones que, al encontrarse, generan el sentido de justicia. Lo cual es patrimonio social, y si bien los técnicos intervienen para ajustarlo en versión de signos jurídicos, tan social sigue siendo que los jueces se hallan ante la expectativa de suscitar un proceso comunicativo -el judicial, en uso de los signos propios del Derecho- para crear o transmitir el sentido de justicia que se respira en la iusphera.

Las evidencias abundan, luego no es difícil traer ejemplos como los matrimonios igualitarios, el estatus jurídico de los Derechos Humanos, la igualdad jurídica de las personas con discapacidad, la titularidad del medioambiente, de la familia y de los animales respecto de derechos, etc. Todo lo cual no es posible más que a consecuencia de un cierto sentido de justicia que, por cierto, pone en entredicho muchos de los aportes hermenéuticos y dogmáticos de los técnicos del Derecho, cuya existencia no depende tanto de la técnica o perfección de su producción, como de otros aspectos entre los cuales las creencias sociales tienen todo que ver ${ }^{57}$.

Por esta razón propusimos que en vez de hablar de semiótica del Derecho se prefiriera semiótica de la justicia, dado que resulta menos "bourdiana" 58 . Claro está, se trata de reconocer el papel fundamental que juegan las sociedades en la producción y práctica del Derecho, lo cual en sí mismo no riñe con el papel que juegan los técnicos del Derecho, pero sí pone más claros los roles reales que les corresponde ${ }^{59}$.

delito de lesiones o de homicidio, para "intuir" algo injusto o todo lo contrario si se experimenta como defensa legítima.

57 Bastida, Xavier (2000). El Derecho como creencia, Bogotá: Editorial Universidad Externado de Colombia.

58 Ya hicimos alguna referencia a que hemos preferido la designación "semiótica de la justicia". Y tal propuesta tiene su propia racionalidad, pues a partir de la constatación de la existencia de un trasfondo, habitus o entorno jurídico, que ha preferido designar "instinto de juridicidad", se ha hallado que el ser humano cuenta con una condición antepredicativa que le permite suscitar estados de conciencia de la función jurídica. Por ello todo ser humano con un estándar ordinario de conciencia puede saber, por ejemplo, que quitarle la vida a alguien más es un delito, pese a no saber discernir la teoría general de delito. Lo mismo que sucede cuando recibe una cosa a cambio de un precio, sabe o intuye que debe pagar el precio justo, sin que ello implique un conocimiento previo de los contratos sinalagmáticos. Dicha condición, verificable en estos y muchos más aspectos jurídicos, es el fundamento de la existencia de la justicia como parte del elemento de la vida social humana, es patrimonio de la conciencia, no de la ciencia, y por lo mismo la semiótica debe considerarla como esencial a la existencia del Derecho. Mientras que "semiótica jurídica" o "semiótica del Derecho", al menos sugieren un contenido técnico que solo considera a los técnicos como precursores de la justicia. Moya, Manuel (2007). Los fallos penales por el delito de inasistencia alimentaria. Un desfase entre la ley y la práctica judicial, Bogotá: Ediciones Universidad Santo Tomás.

59 No deja de suscitar alguna sospecha de identidad con la sociología jurídica. No disputamos que así como hay sinapsis y espacios secantes con la dogmática y la hermenéutica, también los hay entre semiótica y sociología del Derecho. Pero esta persiste en el Derecho como algo meramente técnico, por ejemplo, Bourdieu y Teubner (2000). La Fuerza del Derecho, Bogotá: Ediciones Uniandes. Al igual que la sociología en general, se ha empeñado en considerar como opciones extremas los 
En punto al Derecho penal las inquietudes semióticas indagan por sus signos habituales, como la culpabilidad y la responsabilidad, cómo son operados en los procesos comunicativos que los comprometen, y a qué sentido de justicia terminan respondiendo. Recientemente investigamos en esta perspectiva la incidencia de la Convención sobre los Derechos de las Personas con Discapacidad, sobre el signo penal de la inimputabilidad, y lo que hallamos es que estamos de cara a una resignificación, en donde el sentido de justicia social está proporcionando las condiciones para que los significados como imputables por el Derecho penal se sirvan de un modelo de responsabilidad penal compensatoria.

Este tipo de investigación es la que echamos de menos y a la que decididamente apuntamos, siempre estimando la posibilidad de un Derecho general y un Derecho penal en particular, colmado de humanitas, el ensueño de Beccaria, de Feuerbach, de Kant y de Hegel, los pioneros.

\section{CONCLUSIONES}

La hermenéutica y la dogmática han proporcionado el saber técnico del Derecho, dentro de un rango de cientificidad que comparten con las restantes ciencias sociales y humanas, conforme a unas condiciones dominadas por la racionalidad lógica. Obra sin lugar a dudas cimera y a la cual debemos el grueso del desarrollo de la ciencia jurídica.

No obstante y como ha sido descubierto y hasta lamentado por hermeneutas y dogmatistas, el juego que en ellas ha tenido el ser en su individualidad y la sociedad en su caracterización unitaria no es clara, pues de una u otra forma han confluido en la consolidación de un campo jurídico con las características precisadas a través de las investigaciones de Pierre Bourdieu, conforme con las cuales se trata de un saber confiado a los técnicos, traficantes de unos capitales simbólicos y dueños de un dis-

fenómenos sociales como fruto de conflictos -como en FERRARI, VInCENZO (2002). Acción Jurídica y Sistema Normativo. Introducción a la sociología del Derecho, Madrid: Dykinson, o como elementos que funcionan o disfuncionan dentro de un sistema -como en LUHMANN, NiKLAS (2005). El Derecho de la Sociedad, México: Editorial Herder. En ambos casos, la sociedad aparece como una metonomia, pues unos mandan y otros son mandados, caso en el cual los primeros disponen lo que es el Derecho y la justicia, o las personas son operadoras dentro de la estructura y todo lo que les pasa en su interior es cuestión de psicología, lo cual queda al margen de la iusphera. O en cambio se formulan las acciones comunicativas como una excepción que raya en lo más improbable, es decir, lo que queda más allá de las acciones estratégicas e instrumentalizadoras -como en HABERMAS, JÜRGEN (2002). Acción Comunicativa y Razón sin Trascendencia, Barcelona: Paidós. Mientras que los presupuestos semióticos atienden a hablantes que pueden ciertamente negarse, pero también autoafirmase a través de una vida social, pues entiende que sea en los conflictos o sea en los sistemas, intentan crear su propia versión de sí creando la sociedad a la cual pertenecen. 
curso, en que los legos son excluidos, pues los habitus jurídicos son escenificados nada más que por ellos.

Lo cual se ha traducido en una distancia, nada grata, respecto de la realidad social, en ocasiones vulnerada por una racionalidad inconsulta de las demandas y expectativas que, en materia de justicia, reclaman las comunidades.

La semiótica no desconoce el saber privilegiado de los técnicos; por el contrario, se sirve de ellos, pero a diferencia de la hermenéutica y de la dogmática, parte de la sociedad, para arribar a las instituciones y los principios fundantes del Derecho.

Es así por cuanto su estatuto científico considera los sistemas sígnicos del Derecho, al tiempo que los procesos comunicativos mediante los cuales circula el sentido, y el sentido en sí.

Hay signos jurídicos, entre los cuales se hallan las narrativas y los discursos en general, pero ese sistema de signos tiene por vocación servir a los procesos comunicativos, mediante los cuales se gesta y se circula el sentido de justicia. Luego, el Derecho no es patrimonio de los técnicos, sino de las sociedades de las cuales aquellos hacen parte.

Las investigaciones auténticamente semióticas indagan por los tres, en una unidad compacta manifiestas a través de ellos.

En esa tríada, el sentido ha sido una especie de cenicienta, pues se encuentra particularmente relegado, no tanto porque se haya dispuesto una estrategia orientada a su minimización, sino porque ante las dificultades que registra, se ha preferido suponerlo.

Esta primera aproximación a la semiótica del Derecho, que tiene la pretensión de propiciar una semiótica específica del Derecho penal, reivindica la unidad, y se ha propuesto desatar una base teórica a partir de la cual se homogeinice la trascendencia del sentido, no para disputar un cierto lugar a los signos y los procesos comunicativos, sino para restablecer la completitud que en la tradición semiótica ortodoxa se echa de menos.

En las sociedades, la justicia es hablada tanto por legos como por expertos, y puede que aquellos deban servirse de estos en la precisión de los signos del Derecho, pero la construcción del sentido es social. Si toda metodología, toda epistemología tiene por fin último el sentido de los fenómenos, la semiótica, a diferencia de la hermenéutica y la dogmática, reconoce a las sociedades como gestoras de ese sentido de justicia que circula, incluso en los discursos de los técnicos.

En la semiótica del Derecho emerge redivivo el protagonismo de las comunidades, que inevitablemente hablan del Derecho y en cuyo seno se forja el sentido de justicia. Efecto manifiesto entre otros, en los procesos de individuación de las instituciones. 
De donde constituya la feliz alternativa de desentrañar las implicancias del saber abductivo mediante el cual se forja el sentido de justicia, y permita el discernimiento del fenómeno jurídico informado tanto de lo estrictamente técnico como de lo que no es así.

Tal vez se trate de la retoma de aquellos tiempos cuando se reconocía junto al ius ortodoxo, ese "otro" Derecho manifiesto en el llamado por los antiguos fas, no explicable hermenéutica ni dogmáticamente, pero que en todo caso juegan un rol determinante en los procesos de producción de la justicia. Es, al cabo, la alternativa de humanizar el conocimiento del Derecho, y hacerlo más plausible al fin de la convivencia pacífica, su razón última de ser.

\section{REFERENCIAS}

Barranco, Graciela De Busaniche (1988). La retórica de los interpretantes $C h$. S. Peirce. Cuadernos Gritex.

Barthes, Roland (2010). Mitologías, trad. Héctor Schmucler. México: Siglo Xxi: "La significación es el mito mismo".

Bastida, Xavier (2000). El Derecho Como Creencia, Bogotá: Editorial Universidad Externado de Colombia.

Bourdieu y Teubner (2000). La Fuerza del Derecho, Bogotá: Ediciones Uniandes.

CARnera, AleXÁNDER (2012). Freedom of Speech as an Expressive Mode of Existence. International Journal for the Semiotics of Law. Volume 25, Issue1.

Castañares, Wenceslao (2014). Historia del pensamiento semiótico, Madrid: Trotta, v. 1, 2 y 3 .

Colombia, Corte Constitucional, Sentencias T-153 de 1998, T-388 de 2013 y T-762 de 2015.

Coskun, Deniz (2007). The Linguistic Turn of Social Contract Theory: Ernst Cassirer and the Conditions for the Possibility of a Promise. International Journal for the Semiotics of Law. Volume 20, Issue 2.

De SAint-Exupéry, Antoine (1998). Ciudadela, trad. Hellen Ferro, Barcelona: Alba Editorial, S.L., segunda edición.

Discini, Norma (2015). Corpo e Estilo, Brasil: Editorial Contexto. 
ECo, Umberto (1991). Tratado de Semiótica General, Barcelona. Editorial Lumen. Quinta edición.

FERrari, VinCENZO (2002). Acción Jurídica y Sistema Normativo. Introducción a la sociología del Derecho, Madrid: Dykinson.

FOLEY, RICHARD (2002). Convention as Intention - The Institution in All of Us. International Journal for the Semiotics of Law. Volume 15, Issue 4.

GeERTZ, Clifford (1987). La Interpretación de las Culturas, Barcelona: Gedisa.

Geertz, Clifford (2003). El Surgimiento de la Antropología Postmoderna, Barcelona: Gedisa.

Greimas y Fontanille (1994). Semiótica de las pasiones. De los estados de cosas a los estados de ánimo, trad. Gabriel Hernández Aguilar y Roberto Flórez, México: Siglo XXI Editores, segunda edición.

Habermas, Jürgen (2002). Acción Comunicativa y Razón sin Trascendencia, Barcelona: Paidós.

Halliday, Michael (1994). El lenguaje como semiótica social. La interpretación social del lenguaje y del significado, trad. Jorge Ferreiro Santana, Santafé de Bogotá: Fondo de Cultura Económica Ltda.

Hegel, G.W. Friedrich (1999). Principios de la Filosofía del Derecho. Traductor Juan Luis Vermal, Barcelona: Edhasa.

HUSSERL, EDMUNDO (2013). Ideas relativas a una fenomenología pura y a una filosofía fenomenológica. Libro primero: introducción general a la fenomenología pura, trad. José Gaos, edición y refundición por Antonio Zirión Quijano, México: Fondo de Cultura Económica.

Hutton, Christopher (2009). Meaning, Time and the Law: Ex Post and Ex Ante Perspectives. International Journal for the Semiotics of Law. Volume 22, Issue 3.

Iglesias R., Juan (1993). Derecho Romano, Historia e Instituciones, Barcelona: Ariel Editorial.

Izzo, Valerio N. (2012). Beyond Consensus: Law, Disagreement and Democracy. International Journal for the Semiotics of Law. Volume 25, Issue 4.

Jakobson, Roman (1996). El Marco del Lenguaje, México: Fondo de Cultura Económica. 
Kalinoswski, Georges (1975). Lógica del Discurso Normativo, Madrid: Tecnos,

Kant, Inmanuel (1995). La Metafísica de las Costumbres, traducción de Adela Cortina, Bogotá: REI Andes Ltda.

Kevelson, Roberta (1987). Charles S. Peirce Method of Methods, Amsterdam; Philadelphia: John Benjamins Publishing.

Kevelson, Roberta (2011). The Law as a System of Signs, New York: Editorial Springer.

LANDOWSKI, ERIC (1973). La Sociedad Figurada: Ensayos de Sociosemiótica, México: Univ. Autónoma de Puebla: Fondo de Cultura Económica.

Lévi-Strauss, Claude (1985). Las Estructuras Elementales del Parentesco (II), Barcelona: Planeta Agostini.

Luhmann, NiKLAS (2005). El Derecho de la sociedad, trad. Rafael Torres Nafarrate, México: Herder.

Luhmann, Niklas (2007). La sociedad de la sociedad, México: Herder.

Merleau-Ponty, Maurice (1970). Lo visible y lo invisible, trad. José Escudé, Barcelona: Editorial Seix Barral, S.A.

Merleu-Ponty, Maurice (1984). Fenomenología de La Percepción, Barcelona: Editorial Planeta Agostini.

Moya, Manuel (2007). Los Fallos Penales por el Delito de Inasistencia Alimentaria. Un desfase entre la ley y la práctica judicial, Bogotá: Ediciones Universidad Santo Tomás.

Peirce, Charles (2008). El pragmatismo, trad. Sara Barrena, Madrid: Ediciones Encuentro, S.A.

Puerto, César Fredy Pongutá (2015). Charles Sanders Peirce: conmemorativo en el centenario de su muerte, Cuadernos de Filosofía Latinoamericana, vol. 35, n. ${ }^{\circ} 111$.

Ricoeur, PAul (1990). Between Hermeneutics and Semiotics. International Journal for the Semiotics of Law. Volume 3, Issue 2.

Robles Morchón, Gregorio (2009). Comunicación, Lenguaje y Derecho: algunas ideas básicas de la teoría comunicacional del Derecho, Madrid: Real Academia de Ciencias Morales y Políticas. 
SEARle, John (1997). La Construcción Social de la Realidad, Barcelona: Editorial Paidós.

ShÜTZ, Alfred (1966). Fenomenología del Mundo Social. Introducción a la Sociología Comprensiva, Barcelona: Paidós.

VAn Den Hoven, PAul (1988). Legal argumentation as an illocutionary act complex: A critical analysis. International Journal for the Semiotics of Law. Volume, Issue 11 .

VAN SCHOOTEN, HANNEKE (1996). The meaning of law as instrument. International Journal for the Semiotics of Law. Volume 9, Issue 1.

Von Kutschera, Franz (1979). Filosofía del lenguaje, trad. Adelino Álvarez, Madrid: Gredos.

WARley, Jorge (2007). Semiótica de los Medios. Signo, representación, ideología, política, Buenos Aires: Biblos.

WERnER, WOUTER G. (1995). Legal signs and legal science. International Journal for the Semiotics of Law. Volume 8, Issue 2.

Wittgenstein, Ludwig (2002). Tractatus Logico-Philosophicus, trad. Luis Valdés Villanueva, Madrid: Tecnos, edición 3. 